\title{
Falando de gênero, raça e educação: trajetórias de professoras doutoras negras de universidades públicas dos estados do Ceará e do Rio de Janeiro (Brasil)
}

\section{Talking about gender, race and education: trajectories of black female doctor professors from public universities of the states of Ceará and Rio de Janeiro (Brazil)}

\author{
Joselina da Silva* \\ Maria Simone Euclides**
}

\begin{abstract}
RESUMO
O presente artigo tem por objetivo discorrer sobre racismo institucional e atuação de professoras doutoras e negras em universidades públicas dos estados do Ceará e Rio de Janeiro. Tratamos de equalizar e qualificar o debate, ainda caro na atualidade, sobre práticas de racismo/sexismo em instituições públicas. Para tanto, adotamos como proposta metodológica a realização de entrevistas semiestruturadas com doutoras que se autodeclararam negras. Os relatos esclarecem a persistência do racismo, suas afrontas nas trajetórias docentes, e pontuam o ativismo e as ações coletivas de enfrentamento adotadas por cada professora interpelada nesta investigação.
\end{abstract}

Palavras-chave: Racismo institucional. Docentes negras. Universidades públicas.

* Universidade Federal Rural do Rio de Janeiro. Curso de Licenciatura em Educação do Campo. Seropédica, Rio de janeiro, Brasil. E-mail: joselinajo@yahoo.com.br. https://orcid. org/0000-0002-5159-9055.

** Universidade Federal do Piauí. Curso de Licenciatura em Educação do Campo. Ciências Humanas e Sociais. E-mail: simoneeuclides@yahoo.com.br. https://orcid.org/0000-0002-2409-9303. 


\begin{abstract}
This article aims to discuss institutional racism and the performance of black female professors in public universities in the states of Ceará and Rio de Janeiro. We try to equalize and qualify a debate that is still difficult nowadays; namely, practices of racism and sexism in public institutions. Therefore, we adopted as methodological proposal the realization of semistructured interviews with female doctors who have declared themselves black. The reports clarify the persistence of racism and its insults to teaching careers, while also demonstrating the activism and the collective actions of confrontation adopted by each professor interviewed in this research.
\end{abstract}

Keywords: Institutional racism. Black female professors. Public universities.

A discriminação racial nos alcança nos lugares e momentos mais improváveis e, por mais que tenhamos criado uma espécie de couraça para segurar essa violência, descobrimos nossa fragilidade e que nunca estamos preparados [...]. Afinal, vivemos em um país que a policia e a justiça foram feitas para beneficiar os ricos e os donos do poder. Se a causa for movida por negros, mais rápido a justiça age contra eles.

Thereza Santos

Discorrer sobre o racismo em espaços públicos é ainda um debate muito caro em nossa sociedade, principalmente quando intersecciona a questão de gênero. À medida que assistimos os avanços concernentes à luta histórica dos movimentos sociais negros e de mulheres negras, não necessariamente ficamos isentos de nos deparar com notícias e inúmeros casos sobre discriminação, preconceito ou mesmo a negação de direitos à população afrodescendente ${ }^{1}$.

Espaços públicos e institucionais não estão imunes à lógica de diferenciação e desigualdades entre os indivíduos. Trata-se de ambientes onde a hierarquização e o distanciamento na espacialização passam a ser vistos de forma banalizada e natural. Como, por exemplo, a ideia compartilhada de que o lugar de mulheres negras seja o de serviços subalternizados. Portanto, sendo-lhes negado o direito de assumir outras ocupações no espaço público.

1 Referimos aqui as recorrentes notícias de extermínio da juventude negra em grandes bairros periféricos e aos inúmeros casos de racismo denunciados e anunciados na mídia. Sobre genocídio negro e feminicídio, os dados publicados pelo IPEA, no "Atlas da Violência" em 2017, revelam o crescimento dos homicídios de homens e mulheres negros. Ver "Atlas da Violência", publicado pelo IPEA em junho de 2017. Disponível em: <http://www.ipea.gov.br/portal/images/170602_atlas_da_violencia_2017.pdf >.Acesso em: 10 dez. 2017. 
Buscamos, neste artigo, compreender quais caminhos e enfrentamentos têm sido realizados por mulheres negras que conquistaram o título de doutoras e atuam como docentes em universidades públicas, de modo a identificar os mecanismos de superações e agenciamentos.

O objetivo é apresentar algumas das intervenções realizadas, no que tange ao enfrentamento da problemática racial, mediante suas respectivas atuações e fortalecimento. Para tanto, foram realizadas entrevistas semiestruturadas junto a nove docentes de três instituições públicas federais e estaduais no Estado do Ceará: Universidade da Integração Internacional da Lusofonia Afro-Brasileira UNILAB, Universidade Estadual do Ceará - UECE, Universidade Regional do Cariri - URCA e Universidade Federal do Ceará - UFC. No caso do estado do Rio de Janeiro, foram duas até o momento: Universidade Federal do Estado do Rio de Janeiro - UNIRIO e Universidade Estadual do Rio de Janeiro - UERJ².

De modo a manter o anonimato das docentes negras e fazer jus às suas respectivas lutas cotidianas, resolvemos identificá-las, na pesquisa do Ceará, com os nomes de mulheres negras que na historiografia brasileira trazem como símbolos a luta e a resistência. Dentre elas estão: Dandara, Carolina Maria de Jesus, Nzinga, Antonieta de Barros, Preta Zeferina, Luiza Mahin, Tia Marcelina, Jovelina Perola Negra, Josina Mashel e Filipa do Pará. Já na experiência do Rio de Janeiro, a escolha foi por nomes expressivos que denotem personalidades marcantes, identificando-as até o momento como Aisha e Aziza ${ }^{3}$.

Nota-se uma situação bastante emblemática para mulheres negras na discussão sobre a presença feminina no espaço científico. No que se refere especificamente à inserção da mulher negra no universo acadêmico, percebe-se que nos anos iniciais, há uma sobreposição de mulheres em relação aos homens ${ }^{4}$. Quando se chega, porém, aos graus superiores, nota-se pouca ou quase nenhuma presença do segmento racial negro. Em determinadas situações, a representação de negros e negras encontra-se direcionada a cursos de menor

2 Este artigo apresenta os recortes de duas pesquisas: uma de doutorado, já defendida com a tese intitulada "Mulheres negras, doutoras, teóricas e professoras universitárias: desafios e conquistas" e desenvolvida pela Profa. Dra. Maria Simone Euclides, no âmbito do Programa de Pós-Graduação em Educação da Universidade Federal do Ceará. A segunda, uma dissertação de mestrado - ora sendo desenvolvida pela Profa. Tatiane da Conceição Carneiro - no âmbito do Programa de Pós-Graduação em Educação, Contextos Contemporâneos e Demandas Populares (PPGEduc), da UFRRJ.

3 Aisha significa Vida, e Aziza, preciosa. (Fonte: https://www.geledes.org.br). Por questões de ética e intersubjetivas, não inserimos nesta pesquisa, dados sobre idade das professoras entrevistadas.

4 De acordo com dados divulgados pela pesquisa do INEP, no ano de 2015, de um universo de 378.939 docentes universitários no Brasil, apenas 13,22\% são negros. Desse montante, somente $33,9 \%$ estão em instituições públicas, $54,43 \%$ são de maioria masculina e, em geral, 43,09\% possuem titulação máxima de mestres. (ARBOLEYA; CIELLO; MEUCCI, 2015). 
prestígio na sociedade. Em se tratando exclusivamente da presença feminina, autores como Queiroz (2001) ressaltam que o campo científico ainda é marcado pelo sexismo e a falsa ideia de que fazer ciência é somente privilégio do sexo masculino. Nessa direção, assim nos fala uma das docentes do Rio de Janeiro.

Nossa presença é uma presença outra. Tem grupos que acham que nós nascemos para servir, que nós temos que ser coadjuvantes e não protagonistas. Infelizmente é um dado da sociedade... No caso do Brasil, a população negra é uma população insurgente, em determinados setores da sociedade, nós somos insurgentes. (ARETA, 2017).

Devido às "ausências" de mulheres negras em cargos de professoras universitárias, para mapear criteriosamente trajetórias que romperam com a cadeia das múltiplas discriminações de gênero, raça, classe, dentre tantos outros demarcadores, não foi tarefa difícil encontrá-las. Como bem salientado por uma das docentes entrevistadas, Dandara (2015):

ser mulher e ser professora parece que já vem algo já de tempos consolidado. Como se não fosse um lugar deslocado, uma mulher ser professora. Agora, uma mulher negra ser professora. Eu não estou falando de qualquer professora, eu estou falando de professora de nivel superior [...].

Trata-se de uma ausência reificada pelos órgãos públicos e, de certa forma, não questionada e problematizada quanto ao quesito do ingresso como professoras universitárias e o desafio enfrentado no cotidiano das instituições de ensino superior.

\section{Racismo institucional: para pensar os caminhos destas professoras doutoras}

Um modo de subordinar o direito e a democracia às necessidades do racismo, fazendo com que os primeiros inexistam ou existam de forma precária, diante de barreiras interpostas na vivência dos grupos e indivíduos aprisionados pelos esquemas de subordinação desse último.

Jurema Werneck et al. 
As falas de grande maioria das professoras aqui relatadas nos dão oportunidade para pensar os inúmeros mecanismos através dos quais o racismo toma materialidade. Ademais, os racismos sofridos por estas professoras - tendo indivíduos como agentes diretos, uma vez ocupando o espaço onde são minoria demográfica - acabam por experimentar o que pode ser chamado de racismo institucional, como brevemente definido na epígrafe deste tópico. Sua manifestação dá-se, muitas vezes, ao abrigo do direito, protegendo-se nos meandros burocráticos e alimentando tratamentos diferenciados, com prejuízo para a população negra, indígena, quilombola, entre outros. São perceptíveis também cerceamentos de benefícios, bem como ofertas minoritárias de oportunidades para grupos considerados inferiores na pirâmide racial construída pela sociedade (THEODORO, 2008).

Destarte, pensar a respeito do racismo institucional é inferir que sua manifestação se dá, sobretudo, na efetivação - ou no seu oposto - das políticas públicas, no momento em que seu alcance se diferencia em quantidade, qualidade e efetividade, a depender da raça dos possíveis beneficiários. Sua ação pode ser detectada não apenas pela assunção de presença, pela detecção de seu enunciado ou pela verbalização pejorativa baseada em epítetos relativos à raça. Isto é, diferentemente do racismo individual, o silêncio sobre sua existência pode corroborar sua materialidade.

Lembremos que o conceito de racismo institucional, forjado nos EUA dos anos 1960, pressupunha, desde então, a denúncia de sua presença nas instituições de qualquer âmbito; ou seja, ocorre nas organizações sociais e no seio institucional. Pode ser detectado - segundo Stockley Carmichael e Charles Hamilton, elaboradores dessa teoria - quando os serviços a serem providos por profissionais ou instituições se pronunciam de maneira falha, mediante o fato de a pessoa beneficiária não ter acesso aquele bem ou serviço devido à cor, cultura, raça ou origem étnica.

Nessa direção, como nos lembra Werneck na epígrafe, trata-se de uma forma de racismo que pressupõe fácil detecção, porém de difícil denúncia. Tal ocorre porque se imiscui nas gestões, nas instituições e nos aparatos públicos calcados em grupos e poderes que guardam hegemonia nas estruturas de poder da sociedade. O que estorva seu desvelamento é a ausência de individualidade; ou seja, de sujeitos infratores. Souza (2010), por seu turno, questiona a análise sobre o racismo institucional até aqui apresentada. Segundo o autor, ao largo de ser um fator que se instala nas organizações, após elas serem estabelecidas, nas formas de construção, já ocorre a partir de um sistema racista que se polariza desde o seu nascedouro, em bases excludentes e racializadas.

Oportunamente, vale mencionar que a universidade é um dos espaços onde não caberiam os(as) negros(as), uma vez que cultural e historicamente 
há todo um mito fundante na sociedade ocidental que atribui aos negros a falta de capacidade intelectual e de desempenho. Como resultante, a todo momento pessoas negras têm que provar que são capazes de exercer determinada função (MUNANGA, 2004). Como bem destacado por nossa entrevistada, Luiza Mahin (2015), "há espaços que é normal, entre aspas, ser negros. Então, o espaço da cultura, do esporte é onde se espera que se tenha pessoas negras, mas não na universidade, não no espaço acadêmico, não entre os professores, não entre os pesquisadores".

Assim sendo, torna-se importante destacar que tais docentes contrariam a lógica das privações e negações culturalmente inscritas em seus corpos e mentes. Quando ocupam o espaço acadêmico, trazem uma ruptura também para a epistemologia sobre os ditames da negritude, gênero e ciência. Passam a atuar no universo investigativo, construindo novos saberes, pautados em um conhecimento antirracista, antissexista e anti-homofóbico. Elas fazem valer seus achados, bem como suas pesquisas, em primeira pessoa e não como objetos. $\mathrm{Na}$ qualidade de sujeitas e participantes desses espaços são legítimas para dizer sobre si, como afirma a professora Areta (2017): “O nosso lugar não é ali. Eles olham para você, enquanto professora da pós e olham para moça que trabalha na portaria e se perguntam porque ela está aqui".

O fato de ocuparem uma determinada posição no mercado de trabalho não as isenta de sofrer as mesmas ações experimentadas pela maioria das mulheres negras posicionadas na invisibilidade ou em profissões subalternizadas. Enquanto atitude de negação do outro, o racismo se manifesta tanto em relação ao(s) professor(es) quanto aos discentes e demais sujeitos que compõem este ou outro espaço na sociedade:

O racismo não deixa de existir porque tu tens um título acadêmico [...]. Então, você tem que lidar com essas situações e amparar outras pessoas... Por exemplo, uma aluna minha orientanda que se descobre negra nesse processo de fazer a sua monografia e ela veio com isso tudo e eu estou ali. Nesse sentido são os meninos de uns países africanos com outros contextos históricos de racismo vivenciados aqui em Fortaleza e por ai afora. Eu, sentindo o olhar diferente por vezes comigo, como é essa coisa assim, de você tem que estar sempre se digladiando com essas coisas e sempre lidando com elas. (LUIZA MAHIN, 2015).

Ou seja, mulheres na academia ou mulheres negras afrontando o espaço acadêmico são capazes de fomentar novas resistências em jovens mulheres e negras, mediante a corporificação do que lutam, dizem e vivem. Em algum 
momento, essa situação é exposta por seus colegas de trabalho como algo estranho, como temática, discussão e/ou problematização no espaço acadêmico.

O que não significa que dentro das universidades não existe discriminação racial [...]. O que difere os alunos e professores universitários das outras pessoas é que eles são "intelectuais". E intelectuais, supostamente, não são racistas, ou não se dizem racistas. Na verdade, não admitem o racismo. Os outros, pela falta de conhecimento, acabam falando mais abertamente se gostam ou não. Mas, o público acadêmico e muito difícil que admitam algo dessa natureza. (AZIZA, 2017).

As experiências do cotidiano revelam suas respectivas capacidades de agência e poder, no conjunto de relações raciais e de gênero, nas referidas instituições superiores. Quanto ao caráter político da presença e atuação de mulheres negras nos espaços universitários, o fato de "ascender" e se tornar uma professora universitária não as torna distantes do coletivo ou o desconhecimento das relações conflituosas de raça, sexo e classe. Pelo contrário, a ascensão as leva a estabelecer cada vez mais elos de aproximação diante de investigações do porquê tais questões ainda não foram solucionadas. Atuam, ao mesmo tempo, na procura por estratégias de fortalecimento e enfrentamento.

\section{Para além dos números e presenças: a docência como ativismo}

Ao longo das entrevistas e análises das atuações de professoras universitárias negras, observamos como a presença delas deliberam e estabelecem novas posturas metodológicas e epistemológicas nas universidades públicas. Não é somente estar ali (nas universidades) enquanto número - quantidade de professores negros na docência -, mas se fazer presente no sentido qualitativo, isto é, como pessoas que agora ocupam um lugar de "excelência" na sociedade e, por esse motivo, reivindicam - a partir de suas posturas críticas e reflexivas - novas formas de pensar, falar e dizer sobre a negritude.

Quando você entra num curso na universidade como mulher negra e você não quer pautar as especificidades das relações étnico-raciais, você não quer tratar da questão racial. Você só quer estar lá empregada. 
Você ainda vai ter preconceito, vai sofrer discriminação, mas é menor. Agora, o problema é quando você entra e ainda quer pautar no seu curso o tema das questões das relações étnico-raciais. Então, é dizer eu sou uma intelectual e como mulher negra eu quero validar essa minha parte de mulher intelectual que pensa. Eu não vou fazer só o que vocês estão mandando. Eu vou acrescer a um projeto político do curso, que são as relações étnico-raciais. (DANDARA, 2015).

Quando uma mulher negra ocupa um espaço público como a universidade - até então com predominância de pessoas brancas, sejam homens sejam mulheres -, desperta o desejo e a motivação para as demais também ingressarem nesse espaço. A frase "uma sobe e puxa a outra" - utilizada pelo movimento de mulheres negras brasileiras - eleva no sentido de criar mecanismos específicos para permitir o acesso de outras afrodescendentes. Refere-se a alavancar no trabalho simbólico de mudança na maneira como cada um e cada uma vai se ver nessa escala de oportunidades e direitos, de modo a influenciar as escolhas e as oportunidades profissionais. Trata-se de uma forma de somar forças no combate à solidão que o racismo cotidianamente as fez vivenciar nos âmbitos profissionais.

A atuação e o compromisso com as questões raciais, para algumas de nossas interlocutoras, advêm das experiências vividas ao longo das respectivas trajetórias pessoais, acadêmicas e profissionais. Como, por exemplo, a participação em lutas sindicais, organizações não governamentais, diretórios de estudantes, movimento negro, dentre outros espaços de militância e formação. Como bem mencionado por Josina Maschel - na qualidade de professora universitária que pauta as discussões raciais pelo viés da luta, pela igualdade e pelo respeito -, seu desejo é pensar em propostas interventivas junto às escolas do entorno da universidade, na busca de ressignificar e contribuir para o fortalecimento de identidades negras, principalmente em comunidades quilombolas. É uma construção de resistência que segue em formação durante todo o processo de relação com os demais indivíduos. Portanto, não termina, ao passo que o racismo não deixaria de existir mesmo que haja mudanças qualitativas nos quesitos social e econômico.

Hoje percebo isso mais dos colegas do que dos estudantes. Eu sou a professora mais pigmentada do meu departamento. Ai, você percebe algumas falas. Exemplo, chamar o outro de descabelado ou de colorido, achando que é uma brincadeira ou uma coisa afetuosa. Para mim, isso é muito sério e mostra como o racismo existe e é forte. Você pode conversar 
com outros colegas independente se está na pós-graduação ou não e eles vão te confirmar. As relações com os colegas de trabalho nem sempre são afetuosas. Às vezes são irônicas, tentando te mostrar o quanto você é diferente. (AISHA, 2017).

São reflexos de experiências significativas que perpassaram tanto a trajetória pessoal de se reconhecerem como negras em um contexto de negação e desigualdades, quanto em suas trajetórias profissionais, no que tange a busca de uma identidade e legitimidade como professoras e intelectuais negras. Assim, muito mais do que integrar um ethos já consolidado, quando passam a fazer parte do corpo docente de uma instituição pública de ensino superior, elas priorizam a busca pelo respeito e a criação de um conhecimento prático e politicamente engajado com as adversidades de seu povo, de sua historicidade. Dessa forma, desmistificam discursos ainda embutidos na lógica da democracia racial.

Existe uma coisa chamada ethos da servidão. As pessoas se acomodam pensando que umas têm que servir às outras. E isso incomoda muito dizer que existe racismo. É algo que mexe com a nossa sociedade. É como se você violasse o status quo. É como se já estivesse tudo organizado e estaria você vindo de novo falar de racismo. (AISHA, 2017).

Trata-se de mulheres que desde cedo tomaram consciência de sua condição pelas experiências de racismo vivenciadas, nos mais distintos espaços, e por toda a herança ancestral negada, seja pelo preconceito, discriminação, machismo e sexismo. Produzem, então, um inconformismo que leva a ações concretas que subvertem a lógica das opressões vividas pela maioria dos seus ancestrais. Assim, o perceber-se negro(a) é perceber-se em luta diária não só em defesa de si, mas também de toda a coletividade.

Dessa forma, no departamento onde cada uma está inserida, a discussão sobre a temática racial continua de modo latente combinada às questões de gênero e às problematizações das questões estéticas em ser mulher negra, intelectual e professora universitária. Tais inserções se caracterizam como tentativa de dar respaldo e de multiplicar pesquisas que aprofundem a discussão tanto racial quanto de gênero. Como bem destacado por uma das entrevistadas, é o espaço onde elas se encontram, na qualidade de pesquisadoras, e aglutinam demais estudantes que também vivenciam situações de discriminação e preconceito na universidade. 
Na orientação de bolsistas de iniciação científica, extensão ou de mestrado e doutorado, o compromisso com a propagação das discussões e a contribuição na construção de um conhecimento negro livre das ciladas do racismo e sexismo também são bastante pertinentes, realizadas de forma concreta. Como relatado por Luiza Mahin, o compromisso ético e político culmina com o que cada uma vivenciou e/ou vivencia racialmente no cotidiano das universidades.

Não adianta eu lutar por ações afirmativas se eu não me construir como referencial dentro da universidade e poder acolher outros negros e negras que chegarem lá. Até hoje é que eu digo assim: ó, a negrada tem que chegar até o doutorado. Não basta você chegar até a graduação dentro da universidade, não basta. Eu estou com dois casos recentes de duas mulheres negras que eu conheço. Uma delas, simplesmente, ela não defendeu. Ela perdeu o doutorado. Isso é uma perda coletiva. (LUIZA MAHIN, 2015).

A responsabilidade é redobrada, pois cada uma, a partir de suas trajetórias e reflexões sobre as questões étnico-raciais e de gênero, tem consigo a importância do lugar que estão (a academia) e a realidade de seu grupo racial, ainda pertencentes a uma camada alijada da sociedade. Por conseguinte, cada uma das docentes interpeladas, dentro das suas possibilidades e realidades, lança mão de dispositivos diversos para o enfrentamento de modo a não se intimidarem, reafirmando cotidianamente a sua inserção no universo científico, quer seja no ativismo em sala de aula, quer seja na discussão em seus respectivos grupos de estudos e pesquisas.

Realizam um trabalho efetivo, agregando e abordando as questões da diferença e da desigualdade por várias dimensões. Dessa forma, chama a atenção da academia científica para repensar suas práticas educativas em prol da construção da igualdade e da cidadania para o bem viver, como bem destacou Filipa do Pará (2015):

Compromisso político com essa temática abordando diferentes vieses seja do ponto de vista da pesquisa. Pautar como um tema de pesquisa, seja como projeto de extensão, enfim, a minha atuação. A minha produção dentro da docência do ensino superior sempre foi pautada por esse compromisso, com essa temática assim, solitária ou não. 
Por conseguinte, a docência aqui mencionada vai além da transferência de conhecimento em sala de aula. Refere-se à articulação dos saberes como uma forma diretiva de repensar as relações dentro e fora do espaço escolar, no que diz respeito a questionar "verdades" que diferenciam indivíduos na sociedade. Assim, mesmo diante da "solidão" e as práticas cotidianas em minimizar a presença de mulheres negras, a maneira como cada professora reage ao racismo e sexismo presentes no espaço acadêmico é se afirmando e expandindo ainda mais sua atuação com relação às discussões raciais e de gênero.

Quando cheguei para dar aula olhei na planilha e segui para sala estipulada, cheguei lá, coloquei minhas coisas e comecei a receber os alunos. Logo, chegou uma professora mais antiga que disse que aquela sala era dela. Eu tranquilamente disse que no quadro estava informando que minha aula era naquele local... Ela respirou fundo e pediu para que eu saísse, afirmando que só dava aula naquela sala. Novamente, eu disse que não estava errada. Ela se recusou, iniciou uma discussão, foi falar com a coordenação e eu continuei dando aula. Esse foi um exemplo claro de racismo. Nesse momento, realmente me senti discriminada não apenas pelo fato de ser negra, mas também pelo fato de ser nova na instituição. (AZIZA, 2017).

Em grande parte, essas professoras passam a exigir, a partir de suas inserções e pesquisas, o direito de serem respeitadas efetivamente. É uma presença que incomoda, que não deveria estar ali, por isso, sempre que possível é colocada à prova. Todavia, não se deixam ser "engolidas" pelo sistema hierárquico e segregador. É o caso da professora Dandara que, mesmo diante dos vários embates e desafios, tem consolidado seu grupo de pesquisas sobre questões raciais do qual tem emergido várias investigações e projetos de extensão abordando a temática na Universidade Estadual do Ceará:

O caminho que eu busco de superação (de discriminação e preconceito nos espaços acadêmicos) é fazer a escola. O que eu chamo de fazer a escola é formar pessoas para que voltem para ocupar esse lugar em que eu estou. Porque eu não tenho condições de ficar lá para sempre. Eu tenho que ter mais interlocutores, mais orientandas que vão para o mestrado, que vão para o doutorado e voltem em forma de seleção para ir ocupando esses espaços. E isso é um processo demorado [...]. Mas eles têm que terminar o doutorado. Tem que ter concurso e voltar para 
universidade para ajudar. E estarem espalhados pelo Brasil todo. Meu produto de trabalho mesmo é formar gente [...] com uma consciência crítica em termos de negritude. (DANDARA, 2015, grifos das autoras).

Assim como elas, grande parte de seus alunos não tiveram em suas trajetórias educacionais contato direto com professores negros, consequentemente, passaram a ter uma visão errônea dos espaços ocupados pelos afrodescendentes. Uma vez que agora, como docentes universitárias e, sobretudo, dotadas de um corpo negro e feminino, acabam por se tornarem referências positivas. Assim, o foco é multiplicar possibilidades dentro e fora das universidades mediante discussões que subsidiem a resistência e o respeito às diversidades pela apresentação de agendas até então tabus dentro da universidade. Tais professoras iniciam reflexões sobre gênero e sexualidade, tornando-se referências para os demais alunos(as) negros(as).

[...] as nossas trajetórias eu acho que elas só vão fazer sentido quando elas forem coletivas. Eu penso cada vez mais nisso. Coletiva no sentido que eu digo é a gente não se render ao discurso da meritocracia. Nem ao discurso de um não compromisso social. Duas coisas que eu aprendi via programas de ações afirmativas é que existe a ideia do mérito social. $O$ mérito social é aquilo que te liga a tua comunidade, ao teu povo. Aquilo que você devolve para a sociedade. Aquilo que você recebeu. A minha devolutiva está na sala de aula, é nisso que eu posso colaborar. É nisso que eu acho que é fundamental para gente formar outros negros e negras. (LUIZA MAHIN, 2015).

Ao considerar, em sua ação docente, princípios de igualdade e equidade, elas estabelecem iniciativas concretas de trazer quem está à margem para o centro da discussão por meio de projetos e debates nas instituições. Como bem destacou a professora Filipa do Pará (2015), "é pensar como é que as diferentes formas que você tem de promover alguém, que está sempre em desvantagem [...]". A saber: constituir-se como referência e referencial aos demais alunos(as) no embate contra os ismos e na construção de conhecimentos outros que nos façam sair da margem do pensamento científico eurocêntrico que historicamente nos constituiu. A construção de um conhecimento que não se contenta com o que se tem dito ou produzido até então, isto é, a negação dos povos negros, suas histórias, pertencimento, corporeidade e inteireza. 
Como bem ressaltou Bell Hooks, em seu livro Ensinando a Transgredir: a educação como ato de liberdade (2013), a sala de aula continua sendo o espaço que oferece as possibilidades mais radicais na academia. Espaço de reinvenção, crítica, construção e reconstrução de "verdades" e "ideologias", concernentes a uma ideia de mundo possível, não só pela questão racial e de gênero, mas dentre tantas outras situações cambiantes.

De modo geral, podemos afirmar que, em situações distintas, as docentes mencionadas possuem uma grande relevância em seus dizeres/fazeres quando se pensa em posições galgadas por mulheres negras e a referência para seu grupo racial. Como bem colocado por Nzinga (2015), "uma sobe e puxa a outra"s. Esta fala comunga com toda a trajetória anterior ao universo acadêmico que a docente travou em espaços de militância junto a movimentos sindicais e de mulheres negras. A preocupação não é somente pautar as questões raciais dentro das universidades, mas também na sociedade como um todo.

Nós somos poucas professoras negras na universidade. Nós temos consciência disso no âmbito nacional, no âmbito estadual e na Universidade Regional do Cariri. A maioria é educadora negra e militante do movimento sindical, ou do movimento de mulheres e do movimento negro. Então isso, nos impõe e nos coloca na verdade, uma responsabilidade muito grande. A de elevar o nivel cultural, social e de empoderamento de nossas mulheres. E principalmente, mulheres trabalhadoras e as mulheres negras. (NZINGA, 2015).

Há uma clareza fortemente relacionada às reais condições de acesso e de permanência de jovens negros, sobretudo mulheres negras na academia, bem com as nuances e dilemas raciais vividos no cotidiano por boa parte de negros e negras no Brasil. Dessa forma, a consciência dos desafios e a importância que a sua identidade de mulher negra, docente e intelectual, a cada dia, torna-se mais elaborada a ponto de pensar de modo global e coletivo nos demais sujeitos não brancos que se encontram em posições desprivilegiadas em nossa sociedade. Além da necessidade objetiva - que é a remuneração, o bem viver financeiro não se trata somente de um projeto individual, mas também de um dever/fazer presente em suas práticas pedagógicas profissionais.

5 "Uma sobe e puxa a outra" é uma expressão política e representa a luta do movimento de mulheres negras. Foi também lema e tema da Marcha de Mulheres Negras realizada, no ano de 2015, em Brasília. 
O nosso trabalho é um trabalho que tem que render garantias das condições objetivas que é salário, mas é esse trabalho que dá sentido a uma visão de mundo que é uma construção de um outro mundo possível. Então, eu luto pra eu poder ter dinheiro, pra eu pagar minhas contas, pra eu comer, pra eu poder ter as condições, mas eu luto por um ideal de projeto.... que tem de especifico em nós mulheres negras, uma mulher negra consciente no sentido de querer romper com essa sociedade, com essa discriminação e fortalecer o perfil identitário de nós negros. (ZELMA, 2015).

Mediante a nitidez da dimensão histórica e real quanto à ausência de negros e negras nos espaços públicos, inicia-se um processo de retroalimentação da militância, formando novos sujeitos que possam dar continuidade às propostas de equidade e direitos. Ao corporificar em si e na prática educativa os princípios da africanidade e de luta e enfrentamento passam a se tornar referência para seus alunos e comunidade externa que também anseia por mudanças estruturais. Positivam, então, identidades outrora negadas na sociedade, criando referências outras para trabalhar com a diversidade de sujeitos no contexto educacional.

Nessa nova forma de conceber e pensar a educação enquanto formação de pessoa em sua humanidade e dignidade humana, valores e saberes ancestrais ganham forma para além daqueles da cultura dominante. Sendo assim, tais docentes desafiam a si a criar dizeres e pedagogias para as relações raciais, de maneira positiva e propositiva, reafirmam presenças e identidades afro-brasileiras. Trata-se de uma forma diferenciada e recriada para lidar com as situações adversas do racismo e enfrentá-lo por meio de estratégias de empoderamento e valorização do pertencimento étnico-racial.

\section{À guisa de conclusão}

As professoras doutoras negras - docentes de universidades públicas federais ou estaduais dos estados do Ceará e Rio de Janeiro - aqui interpeladas - reconhecem e sabem da representação social do privilégio e do "lugar" que agora ocupam. Elaboram estratégias de potencializar e incentivar a participação de estudantes negros e negras em seus respectivos espaços de atuação. Seguimos sendo poucas, nos espaços acadêmicos institucionais, por esse motivo, somos protagonistas importantes na propulsão de demais sujeitos negros/negras. Muito mais do que integrar um ethos já consolidado sobre o pensar e o fazer científico, mulheres negras nos espaços acadêmicos podem priorizar o respeito 
e a legitimidade de um conhecimento prático e politicamente engajado com as adversidades de seu povo, de sua historicidade.

Apesar de serem carreiras que podem ser identificadas por ausências, tais trajetórias não devem ser encaradas pelo olhar do exótico ou da exceção que confirma a regra, mas de histórias que motivam a assunção de novas ações e gerações de jovens negras universitárias. Mais do que isso, trata-se de evidenciar trajetórias de mulheres negras recriando e transformando o espaço científico, chamando a atenção para dilemas e problemas que não deixaram de existir, como o racismo e o sexismo.

Cada uma integra um segmento da sociedade que vem rompendo com os estereótipos e pré-conceitos sobre mulheres negras no universo científico, trazendo também novas discussões para pensar a mulher negra em inúmeras possibilidades e situações. Todavia, algumas de nossas entrevistadas precisaram pagar e continuam pagando, ainda hoje, o preço de serem questionadas pelos padrões sociais convencionais, se afirmando cotidianamente como, por exemplo, o de "ser uma boa mãe" e uma "boa esposa". Dito em outras palavras, seguem sob alguns julgamentos públicos como aqueles que as criticam por não estarem constantemente presentes durante a formação dos(as) filhos(as), bem como atenção ao cuidado das casas e dos maridos, como é exigido das mulheres na sociedade patriarcal. Consequentemente, não se trata somente de professoras, mas, sim, de mulheres negras que além de romper com a "normalidade", constituídas de suas corporeidades e historicidades, interrogam e afrontam a academia, dizendo sobre as múltiplas formas de negação de seu pertencimento étnico-racial e de gênero e constituindo novas reflexões epistemológicas.

Portanto, os relatos nos levam a pensar e a problematizar o lugar da academia e seu papel perante a sociedade e a "assunção" de seus educandos(as) e educadores(as) na atualidade. Repensar uma universidade e uma escolarização que não só possibilite o ingresso de negros e negras no ensino superior, mas também que lhes dê suporte para se enxergarem politicamente, como também se vejam representados nas mais diversas esferas públicas e de poder.

\section{Agradecimentos}

Agradecemos os depoimentos das seguintes professoras doutoras negras, sem as quais as duas pesquisas que originaram este artigo não seriam possíveis: Sônia Beatriz dos Santos, Claudia Miranda, Zelma Madeira, Cícera Nunes, Zuleide Queiroz, Sandra Petit, Geranilde Costa, Rebeca Alcântara, Telvira da Conceição, Vera Rodrigues e Fátima Vasconcelos. 


\section{REFERÊNCIAS}

ARBOLEYA, A.; CIELLO, F.; MEUCCI, S. "Educação para uma vida melhor": trajetórias sociais de docentes negros. Cadernos de Pesquisa, São Paulo, v. 45, n. 158, p. 882-914, dez. 2015. Disponível em: <http://dx.doi.org/10.1590/198053143248>. Acesso em: 30 jul. 2017.

HOOKS, B. Ensinando a transgredir: a educação como prática de liberdade. Tradução de Marcelo Brandão Cipolla. São Paulo: WMF Martins Fontes, 2013.

MUNANGA, K. Negritude: usos e sentidos. São Paulo: Autêntica, 2004. 93p.

QUEIROZ, D. M. Raça, gênero e educação superior. 2001. Tese (Doutorado em Educação) - Universidade Federal da Bahia, Bahia, 2001. Disponível em: <http://www. redeacaoafirmativa.ceao.ufba.br/uploads/ufba_tese_2001_DMQueiroz.pdf $>$. Acesso em: 20 ago. 2017.

SANTOS, T. Malunga Thereza Santos: a história de vida de uma guerreira. São Carlos EdUFSCAR, 2008. 143 p.

SOUZA, A. S. de. Racismo Institucional: para compreender o conceito. Revista ABPN, v. 1, n. 3, p. 77-87, nov. 2010. Disponível em: <abpnrevista.org.br/revista/index.php/ revistaabpn1/article/download/272/252>. Acesso em: 10 out. 2017.

THEODORO, M. (Org.). As politicas públicas e a desigualdade racial no Brasil: 120 anos após a abolição. Brasília: IPEA, 2008.

WERNECK, J. et al. Racismo institucional: uma abordagem conceitual. Geledés - Instituto da Mulher Negra, 2013. Disponível em: <http://www.onumulheres.org.br/wp-content/ uploads/2016/04/FINAL-WEB-Racismo-Institucional-uma-abordagem-conceitual.pdf>. Acesso em: 5 nov. 2017.

Texto recebido em 27 de março de 2018.

Texto aprovado em 18 de maio de 2018 . 